\title{
Greens or Space Invaders: Prominent Utopian Themes and Effects on Social Change Motivation
}

\begin{abstract}
One way in which individuals can participate in action to change the society they live in is through the pursuit of an ideal society or 'utopia'; however, the content of that utopia is a likely determinant of its motivational impact. Here we examined two predominant prototypes of utopia derived from previous research and theory - the Green and Sci-Fi utopias. When participants were primed with either of these utopias, the Green utopia was perceived to entail a range of other positive characteristics (e.g. warmth, positive emotions) and - provided it was positively evaluated - tended to elicit both motivation and behaviour for social change. In contrast, the Sci-Fi utopia was associated with low motivation, even when it was positively evaluated. Furthermore, the Green utopia was shown to elicit greater perceptions of participative efficacy, which in turn predicted the increase in social change motivation.
\end{abstract} (142 Words)

Keywords: utopia, collective action, social change, culture 
A potential motivational basis for cultural change is a person's vision for an ideal society, or utopia. An ideal society may act as a collective version of an ideal self (e.g., Higgins, 1987; Markus \& Nurius, 1986), and may thus motivate collective action to achieve it. In a recent paper, Fernando et al. (2018) showed that people who tend to engage in utopian thinking have stronger intentions to engage in citizenship behaviours for social change, and that people became more motivated to engage in social change behaviours when they were asked to imagine their own ideal society.

Utopian theorists have repeatedly highlighted the role of utopian thinking in the lives of ordinary people (Levitas, 1990; Sargent, 1994) and in social change (Chomsky, 1970/1999; Mannheim, 1991; Polak, 1961). And while Fernando et al.’s (2018) research attests to the power of utopian thinking as a motivator for social change, utopian theorists have warned that not all utopias motivate people to improve their society, and may in fact undermine motivations for change, driving complacency or inaction (e.g. Bloch, 1986; Levitas, 1990; Mannheim, 1991). Particularly relevant in this context is Levitas' (1990) seminal work in which she postulated that there are three functions of utopia: change, criticism, and compensation. Thus, while some utopian visions motivate social change and collective action, others may elicit a more escapist or complacent response.

We suggest that a critical factor in the differential motivational effects of utopian thinking is the content of utopias: different visions of an ideal society may motivate change to the current society to a different degree. Researchers of contemporary utopian writings (e.g. de Geus, 1999; Garforth, 2005; Stableford, 2010) have observed that science and technology, on the one hand, and ecology, on the other, form two major themes in modern utopian thinking. For example, in his introduction to The Faber Book of Utopias (1999), John Carey describes an 'ultimate conflict' in contemporary utopian ideals as between what he calls 'space-invaders' and 'greens': those who favour human-centred systems and those who 
support a diminished influence of humans on the planet. Thus, there are two prominent visions in contemporary writings about utopia, which we call the Sci-Fi and Green utopias.

In this paper, we examine whether these utopian visions have differential impacts on people's motivation to engage in action to change their society. In doing so, we consider how utopian thinking is relevant to, but applicable beyond, collective action as conceptualized in contemporary social psychology (e.g., van Zomeren, Postmes, \& Spears, 2008; van Zomeren, Kutlaca, \& Turner-Zwinkels, 2018). In particular, we argue that utopian thinking is a process that generates a cognitive alternative - a cognitive representation that presents an alternative to the status quo, without which social change may not occur (Tajfel \& Turner, 1979). But we further contend that the behaviour motivated by a utopian cognitive alternative will not necessarily be of the group-based kind traditionally studied in social change processes. We then investigate how the nature of the cognitive alternative generated - the content of utopia determines whether utopian thinking is translated into collective action. In doing so, we adapt van Zomeren, Saguy, and Schellhaas's (2013) concept of participative efficacy as a key driver for moving from utopian thinking to utopia-motivated behaviour.

\section{The Sci-Fi Utopia and Green Utopias}

Davis (1981) characterised utopias as different ways of overcoming what he called the 'collective problem' - the conflict between the limited available resources and potentially unlimited human desires. As we will argue, the Sci-Fi and Green utopias resolve this problem in different ways: the Sci-Fi utopia through abundance, and the Green utopia through sufficiency.

In many utopian texts, science and technology solve Davis' collective problem by creating material abundance; that is, removing limits on material satisfactions. Kumar (1987) cites Campanella's 1602 City of the Sun as the first utopia where science and scientific 
research are central elements; however, the genre of what we would now call science fiction is approximately 200 years old (Fitting, 2010). H.G. Wells is cited as the leading proponent of the scientific utopia, with his visions of highly planned societies guided by elite scientific knowledge (see Kumar, 1987). Later versions of these same fantasies took on a more antiutopian - distorted or satirical - form (e.g. Aldous Huxley’s Brave New World, Yevgeny Zamaytin's $W e$ ); however, technologically optimistic utopian texts continue to be produced, especially within the genre of science fiction (Segal, 2012), including the world depicted in Star Trek (Kozinets, 2001).

In contrast, the Green utopia represents an alternative of 'sufficiency' (de Geus, 1999), resolving Davis' collective problem through restraint and the substitution of nonmaterial for material satisfactions. Indeed, for several centuries, ecological thinking has provided a counterpoint to utopian visions of material abundance and social advancement enabled by science and technology (see Stableford, 2010). Arguably, the Green utopia can be traced back to the Ancient Greeks and the myths of Arcadia; poetic representations of harmony with nature (de Geus, 1999; Kumar, 1987; see Pepper, 2007, for a review). Some theorists view these ancient myths and modern green utopias (or 'ecotopias') as comprising a single ecological theme in utopian thinking, united by the aforementioned principle of sufficiency (see Garforth, 2005). This contrast in utopian ideals - nature v. science and technology - is echoed in research which has shown evidence of a negative relationship between faith in science and pro-environmental attitudes (e.g. Dunlap \& Van Liere, 1984; Kilbourne, Beckmann, \& Thelen, 2002; Xiao, 2013). As Kaplowitz, Lupi, Yeboah and Thorp (2011) have noted, so ingrained is the perceived conflict between pro-environmental attitudes and attitudes favouring technological and economic growth, that these are often presented as dichotomous choices in research and theory on the topic. 
Many modern ecological utopias, however, are not anti-science and technology, but instead envision more inventive ways of using modern technology in an environmentallyfriendly way (see Garforth, 2005; Pepper, 2007). These are more consistent with an ecological modernization perspective in which technological development is crucial to solving ecological problems. In these views, green technologies (e.g. solar, wind power) are used to sustain the natural environment while stimulating economic growth (e.g. Mol \& Spaargaren, 2000; Spaargaren \& Mol, 1992), thus drawing technological and ecological themes together to overcome the assumed antagonism between economic progress and environmental management (Cohen, 1998; Fisher \& Freudenburg, 2001). Given the ancient roots, and nostalgic connotations, of the Arcadian style of Green utopia, as well as our interest in the motivational capacity of contemporary utopian visions, we will focus here on the modern version of the Green utopia.

What, then, are the fundamental elements of the Green and Sci-Fi utopias which may drive the psychological response to, and motivational effects of, these utopian visions? First, another way to express the principles of abundance and sufficiency is to describe the Sci-Fi utopia as embodying a maximization principle (increasing levels of leisure and material comfort), and the Green utopia as embodying a moderation principle (balancing human comfort and technological development with ecological sustainability). While it has often been assumed that people are guided by a maximization principle, recent research (Hornsey et al., 2018) has shown that a relatively small percentage of people follow a maximization principle in ideals for the self or society. In a study across several countries, Hornsey and colleagues showed that people's ideal levels of positive qualities for the self (e.g. personal health, freedom, happiness) and society (e.g. friendliness, technological advances, national security) cluster around $70-80 \%$ of the way between the total absence and total presence of those qualities. A comparison of the Green and Sci-Fi utopias represents a further test of the 
appeal of a moderate or maximal ideal society, but using richer, more articulated visions of those societies. Existing research on ideals for society or collective futures have tended to examine utopias as either content-free societies onto which participants project their ideal traits (Fernando et al., 2018; Hornsey et al., 2018), or narrow versions of possible societies characterised by specific legislative or population-based changes (Bain, Hornsey, Bongiorno, Kashima \& Crimston, 2013). A next step is to examine how people respond to content-rich versions of utopia: a maximising Sci-Fi utopia versus a moderating Green utopia.

A second key variable in determining the motivational effects of a utopian vision is people's evaluation of that utopia. People must evaluate a utopian image positively for it to act as a goal towards which they would strive. This is a foundational postulate of theories of self-regulation (e.g. Carver \& Scheier, 1998; Higgins, 1987), particularly the expectancyvalue model of goal motivation (see Feather, 1982; Karau \& Williams, 1993). Consistent with this reasoning, Fernando et al., (2018) found a motivating effect of utopian thinking generally; participants in that study were thinking about their own utopian vision which, by definition, they must have evaluated positively.

\section{Utopian Thinking and Collective Action}

As we noted at the outset, utopian visions can be understood as cognitive alternatives to the status quo. In the social identity tradition, a cognitive alternative is a critical feature necessary for social change that emerges in response to perceived insecurity in the status quo, and which influences the development of change-oriented social identities (Tajfel \& Turner, 1979; Reicher, Haslam, Reynolds \& Spears, 2012). Van Zomeren et al. (2008) propose that this process occurs as a pre-cursor to the development of perceptions of group-based injustice and efficacy, but beyond this articulation, cognitive alternatives remain unexamined in social change research (see van Zomeren et al., 2018). However, as Jost, Badaan, Goudarzi, 
Hoffarth and Mogami (2019) noted in their recent commentary on system justification theory, utopian visions represent a form of cognitive alternative that can be investigated in detail.

Utopian visions are ideals for collectives, and therefore we can consider the pursuit of utopian visions as a form of collective action. Because cognitive alternatives can develop well in advance of a sense of social identity, however, behaviour motivated by utopian visions does not necessarily fall within the standard forms of collective action conceptualised within the current literature (such as the Social Identity Model of Collective Action, SIMCA; e.g., van Zomeren et al., 2008; 2018). Collective action has typically been conceptualised in social psychology as action taken by members of disadvantaged groups to improve the conditions of that group (see Wright, Taylor \& Moghaddam, 1990). And although this definition has been expanded over time (see van Zomeren \& Iyer, 2009; Wright, 2009), group identification and group-based disadvantage or injustice remain integral to collective action research (Klandermans, 1997; Mummendey, Kessler, Klink, \& Mielke, 1999; Simon et al., 1998; Van Zomeren et al., 2008). Four key components of collective action have been identified (and are relatively common across various conceptualisations of collective and political action, see van Zomeren, 2016): group identification, group efficacy beliefs, groupbased injustice (elsewhere, group-based anger; see van Zomeren, 2019) and moral conviction. We argue that, while all of these elements may be relevant in some cases, utopian thinking encompasses a broader set of issues which are not always captured by group-based concerns.

First, the identification component of collective action implies that the formation and pursuit of the goal is driven by group memberships or the perception of the self in group terms. Our conceptualisation of utopian visions as cognitive alternatives suggests, however, that utopian visions can exist prior to the formation of group-based identities. That is, utopian visions can represent goals for collectives, rather than collective goals, since the utopian motivation need not be derived from the concerns of a particular group. While some utopian 
visions may be strongly driven by a definable collective in society (e.g. feminist utopias), it is certainly not a necessary feature of utopian thinking. Nevertheless, utopian visions may drive identification with relevant social movements and action groups, as proposed by Thomas, Mavor and McGarty (2011) in the Encapsulated Model of Social Identity in Collective Action (EMSICA). Again, however, we would argue that for utopian visions, this need not necessarily occur, or would require some additional processes. Indeed, Smith, Thomas and McGarty (2015) describe such a process whereby the communication of, and agreement about, a perceived conflict between 'the way things are, and the way things should be' can set in train the processes of identity formation around a new group identity.

Similarly, while utopian visions can be addressed to overcoming existing injustices, this is certainly not a necessary feature of utopian visions, which may, indeed, be broadly supportive of existing societal trends, or advocate for an expansion of current developments in society (the Sci-Fi utopia may be considered an example of this). Thus, the pursuit of 'the way things should be' may be framed in other ways, such as the pursuit of a better lifestyle, or to ameliorate the negative effects of climate change.

Regarding the role of moral conviction (or more broadly, values), the conceptualisation of its role in collective action has been of violation (see van Zomeren, Kutlaca \& Turner-Zwinkels. 2018), consistent with the importance of intergroup injustice. The Green and Sci-Fi utopias represent complex instantiations of values which individuals may hold strongly (environmentalism and scientific development at a concrete level, and maximisation and moderation at a more abstract level), so we can regard the utopias themselves as the value component; however, it is by no means the case that this value is a moral one, much less a reaction to a moral violation. One can easily imagine cases where the utopian value (e.g. extreme material abundance) does not have a strong moral connotation. 
For these reasons, we view group identification, intergroup injustice and moral conviction as factors which are not essential to utopian thinking and motivation. A component of collective action models which is likely to play an important role, however, is efficacy beliefs. We will, therefore, focus on this as the primary mechanism in this research.

\section{Participative Efficacy}

Central to many theories of collective action and achievement motivation is the concept of efficacy. The beliefs people have about their, or their group's, capacity to achieve an ideal have been shown to be an important predictor of action towards the achievement of a personal or collective goal (Bandura, 1982; also see van Zomeren, Spears, Fischer, \& Leach, 2004; van Zomeren et al., 2008), and are a key component of fantasy realisation research (Oettingen, 2012) - in which Fernando et al.'s (2018) investigation of utopian thinking was grounded. Typically, efficacy is conceptualised as a belief about one's ability to produce desired outcomes (Bandura, 1986), often based in previous experiences of achieving similar goals (e.g. performing well on a test). Achieving a utopian society, however, is something of which people will have no prior experience, nor are they likely to have any expectation of actually experiencing success in achieving that goal. Thus, a different kind of efficacy belief is likely to drive utopian social change motivation.

Recent research has shown participative efficacy to predict collective action tendencies independent of group and individual efficacy (van Zomeren, et al., 2013). Participative efficacy refers to the belief that one's contribution to collective efforts can make a difference. This kind of efficacy can be dissociated from beliefs about whether or not the goal is likely to be achieved, and is thus a form of efficacy more likely to be activated in pursuing a utopian goal. However, given the prominence of group identification in collective action models, participative efficacy has been conceptualised and measured as the capacity 
for an individual to make a difference as part of a group (e.g. "I believe that I, as an individual, can contribute meaningfully so that (students) can achieve their common goal of (stopping the financial cuts to higher education)"). As discussed, group identification is not a necessary element of utopian thinking, so a slight modification of the participative efficacy concept is required for this context, which does not require the specification of a group identity. Thus, we conceptualise participative efficacy as the capacity for ordinary people to make a difference in changing their society to approach the utopian vision. This would be consistent with research showing that the perception that ordinary citizens can act to alter collective futures is a critical factor in motivating social change activities (Bain et al., 2013).

There are reasons to believe that the Green utopia may elicit greater perceptions of this kind of participative efficacy. First, the Green utopia is likely to be seen as achievable only by active engagement in social change because people tend to assume a trajectory of environmental degradation when asked their predictions about future societies (Fernando, Burden \& Kashima, 2019). By contrast, research on folk theories of social change suggests that there is a widespread belief that a technologically advanced society will happen if things continue as they are now (e.g., Kashima, et al., 2009, 2011) and it therefore does not require social action. This does not mean that the Sci-Fi society of utopian abundance is viewed as inevitable - the advancement of technology may not proceed in the specific direction of the Sci-Fi utopia or may, indeed, have a more dystopian outcome - but that the Sci-Fi utopia is more consistent with lay beliefs about trajectories of societal change. Second, the Sci-Fi utopia may be seen as dependent upon the development of advanced science and technology, in which most ordinary people cannot participate. 


\section{Study 1}

In Study 1, we explored the capacity of the two utopia prototypes - Green and Sci-Fi - to elicit social change motivation. We developed a measure of Levitas' three functions of utopia - compensation, criticism and change - and examined the capacity of the Green and Sci-Fi utopias to activate these motivations. We also sought evidence for actual behavioural consequences of priming with these two utopias. In addition, we examined participants' tendency to elaborate on broader themes associated with these utopias by measuring the ascription of a range of characteristics to those societies and their inhabitants.

\section{Participants}

One hundred and twenty-four participants were recruited via Amazon's Mechanical Turk for this study. A sensitivity power analysis using $\mathrm{G}^{*}$ Power 3 software indicated a minimum detectable effect size of $\eta_{p}^{2}=.075$ (medium effect) where $1-\beta=.80$. There were 61 males, 62 females and one participant did not specify their gender. Participants had a mean age of 33.73 years $(\mathrm{SD}=10.98)$ and one participant did not provide their age.

\section{Procedure}

Participants were allocated to one of three conditions - Green, Sci-Fi or control. In the Green utopia condition, participants were presented with the following description of an ecologically friendly society, emphasising sustainable technology and material sufficiency.

We would like you to imagine life in an ecologically friendly city of the future. This society harnesses clean energy sources and sustainable technology to ensure citizens enjoy a healthy natural environment free of pollution, where people live alongside spaces provided for abundant plants and animals and are careful to ensure that these 
habitats are preserved and looked after. In this society there is just enough to share so that nobody lives in poverty.

In the Sci-fi condition, participants were presented with the following description of a technologically advanced society, emphasising technological advancement and material abundance.

We would like you to imagine life in a technologically advanced city of the future. This society harnesses immense energy sources and advanced technology to ensure citizens enjoy a sophisticated, abundant lifestyle free of material limitations, where people live alongside advanced computers, robots and appliances which fulfil almost every possible human need and desire. The society is prosperous and everyone has access to material wealth.

Participants were asked to imagine as vividly as possible, and to write a few sentences describing, what life would be like in that society. In the control condition, participants were asked to describe an ordinary day in their life. Participants in the utopia conditions then completed a four-item measure of their Evaluation $(1=$ strongly disagree, $7=$ strongly agree $)$ of the depicted society (e.g. 'This is the kind of society that I would love to live in', 'I find the life and world described to be unappealing. '). Negatively phrased items were reverse coded, and all items were averaged to compute Evaluation $(\alpha=.96)$.

Then, to encourage participants to elaborate on their thoughts, and to examine the broader perceptions participants had of those societies, participants in all conditions rated the life and world they described on a range of characteristics representing six domains: four items measured warmth (warm, friendly, honest, trustworthy, $\alpha=.89$ ); five items measured competence (competent, efficient, confident, organized, capable, $\alpha=.85$ ); four items measured social dysfunction characteristics (see Bain et al., 2013) (corruption, homelessness, 
crime, violence, $\alpha=.87$ ); five items measured social progress characteristics (peace, freedom, fairness, democracy, equality, $\alpha=.78$ ); three items measured negative emotion (stress, depressed feelings, anxiety, $\alpha=.82$ ); and three items measured positive emotion (happiness, calmness, contentment, $\alpha=.82$ ).

Earlier, we noted that Levitas (1990) proposed three functions of utopia: compensation, criticism and change, and that utopian thinking has been shown to elicit these functions (Fernando et al., 2018). Participants completed nine items designed to measure the three utopian functions, with three items assessing each function (see Appendix A for a full list of items). A principal components analysis with oblimin rotation showed the items to form three clear factors corresponding to Compensation $(\alpha=.78)$, Criticism $(\alpha=.78)$ and Change $(\alpha=.88)$. All items had loadings of greater than .65 on the relevant factor, and there were no cross-loadings greater than .30 . In a pilot study $(\mathrm{N}=104)$, these factors were found to be correlated with the measures used in Fernando et al.'s (2018) research on utopianism and social change motivation. In particular, the change factor was highly correlated with citizenship behaviour $(r=.79)$, which was measured as participants desire to perform various actions to change their society. It was also negatively correlated with measures of satisfaction with society $(r=-.23)$ and system justification $(r=-.31)$; thus, we can assume that this factor is a good indicator of general social change motivation.

After a brief demographic survey, participants were told that they would be paid a bonus $\$ 1$ in addition to their payment for participation, but that they had the opportunity to donate some or all of that bonus to any of four charities: the Sierra Club (an environmental not-for-profit organization), the Public Broadcasting Service (PBS), the Salvation Army, or the Cancer Society. The logo of each charity and a brief description of their activities were presented, and participants were instructed to enter the amount (in cents) that they wished to donate to each charity. Any remaining amount was paid to participants as a bonus. 


\section{Results}

First, we compared the two utopian conditions on Evaluation; an independent samples t-test showed that there was no significant difference between the Green utopia $(M=5.02$, $S D=1.77)$ and the Sci-Fi utopia $(M=4.50, S D=2.11)(t(80)=1.22, p=.23, d=.27)$. Next, we examined the characteristics ascribed to each of the utopian societies. Given that participants were likely to attribute more positive characteristics to a utopian society which they generally evaluated positively, we regressed the society ratings on a binary Condition variable (Green $=$ 1, Sci-Fi =0), Evaluation and the Condition $\mathrm{x}$ Evaluation interaction (see Table 1). As expected, Evaluation was a significant predictor of all six characteristics; however, the Green utopia was also an independent predictor of greater warmth, social progress and positive emotion, and lower negative emotion. There was also a significant Condition x Evaluation interaction for competence. Analysis of simple slopes showed that in both the Green and SciFi conditions, there was a significant positive relationship between Evaluation and attributions of competence; however, this relationship was stronger in the Green $(t(78)=$ $5.28, \mathrm{p}<.001, d=1.20)$ than in the Sci-Fi condition $(t(78)=3.14, \mathrm{p}=.002, d=0.71)$.

Table 1 about here

We next examined the motivational consequences of imagining the two utopias. Oneway ANOVAs comparing the three conditions showed no significant differences between conditions for the utopian functions (see Table 2). 
Since we hypothesised that utopias would be motivating when evaluated positively, we regressed the three utopian functions on the same predictors as in the society characteristics analysis. There was a significant effect of Evaluation on Compensation $(\beta=$ $.40, p<.01)$, but no Evaluation $\mathrm{x}$ Condition interaction $(\beta=-.06, p>.05)$. There were no significant main effects of Condition or Evaluation on Change and Criticism, however, the Condition $\mathrm{x}$ Evaluation interaction term was significant for Change $(\beta=.30, p<.05)$ and was also a marginally significant predictor of Criticism $(\beta=.28, p<.06)$. Simple slopes analysis for Change showed that in the Green condition there was a significant, positive effect of Evaluation on Change $(t(78)=3.92, p<.001, d=0.89)$, but no effect in the Sci-Fi condition $(t(78)=1.16, p=.27, d=0.26)$.

Finally, we analysed the effect of imagining the Green and Sci-Fi utopias on donations to charity. Since several participants did not donate any of the $\$ 1$ bonus, the donation measures were positively skewed (skewness $=1.10-4.23$, SE of skewness $=.22$ ), so a binary variable ( $1=$ donation, $0=$ no donation) was created for donations to each charity. The percentage of participants who made some donation to each charity is as follows: Sierra Club, 26.8\%; PBS, 28.0\%; Salvation Army, 25.6\%; Cancer Society, 35.4\% (note that participants could spread their donation across multiple charities). Binary logistic regressions were then conducted to determine the relationship between Condition, Evaluation and the Condition x Evaluation interaction, and the binary donation variables (see Table 3).

Table 3 about here 
There were no main effects of Condition or Evaluation, however the Condition $\mathrm{x}$ Evaluation interaction was significant for donation to the Sierra Club and marginal for donation to PBS. Figure 1 shows a positive relationship between Evaluation and the probability of donation to the Sierra Club in the Green condition, but not in the Sci-Fi condition.

Figure 1 about here

\section{Discussion}

Study 1 showed that, while utopian thinking may elicit a positive effect on motivation for social change (Fernando et al., 2018), this is affected by the content of that utopia. The Green utopia - when positively evaluated - predicted greater change motivation; however, the Sci-Fi utopia showed no relationship with motivation, even when positively evaluated. In this study, we also showed that the motivation elicited by the Green utopia was translated into behaviour in the form of charitable donation. As one might expect, this effect was only observed for a charity related to the content of the Green utopia (the Sierra Club - a proenvironmental organization). A positive evaluation of the Sci-Fi utopia did not predict charitable giving.

Further to the demonstrated motivational effects of the Green utopia, we observed that the Green utopia tended to be appraised more positively than the Sci-Fi utopia on a variety of criteria not specifically related to the content of the utopian visions presented to participants. The Green utopia was perceived to entail more warmth, positive social characteristics (like peace and equality) and positive emotions, and less negative emotions than the Sci-Fi utopia. 
Indeed, the Sci-Fi utopia was viewed as lower in warmth than participants' ordinary lives. These findings held when controlling for participants' overall evaluation of the utopian societies, suggesting that each of these utopias entailed broader connotations which were not simply reflections of participants' liking for that utopia. In general, while the Green utopia was seen as facilitating a more peaceful and harmonious society, the realisation of the Sci-Fi utopia was perceived to come at a cost to traits like interpersonal warmth and societal peace and order. The finding that the Green utopia was perceived as more warm, and as increasing societal change motivation, is consistent with Bain et al. (2013), who found that the perceived benevolence (incorporating warmth and morality) of potential future societies was consistently associated with attitudes and behavioural intentions promoting the achievement of those future societies.

Limitations of this study include, firstly, that the study was somewhat underpowered, which may explain our inability to detect main effects of the utopia manipulation on evaluation and utopian functions; and secondly, that we examined general social change motivation, rather than motivation within specific domains related to the two utopia prototypes. In addition, we have not investigated any possible mechanism for the motivational effects of the Green utopia. These are all addressed in Study 2.

\section{Study 2}

In Study 1, we demonstrated the positive effect of the Green utopia on general social change motivation, but also a domain-specific effect on actual behaviour. In Study 2, we further examine the domain specificity of utopian motivation by measuring the effect of the two utopian visions on strivings. 'Strivings' are superordinate themes which organize and integrate more specific, related goals (Emmons, 1986; Emmons \& King, 1989). For example, environmental strivings are a specific type of striving directed towards environmental 
sustainability, which Kashima, Paladino and Margetts (2014) found to be predictive of a wide range of pro-environmental behavioural intentions. We expect that environmental strivings will be elicited by the Green utopia. And although the Sci-Fi utopia showed no association with general social change motivation, we speculate that the Sci-Fi utopia may be associated with economic striving (since economic development supports, and is supported by, scientific and technological development) and/or personal life strivings (given the association between the Sci-Fi utopia and material abundance). Given the social change motivation elicited by the Green utopia in Study 1, we also assessed pro-environmental citizenship intentions as an alternative measure of this motivation.

In addition, we examined the role of participative efficacy as a mechanism by which the content of utopia may affect social change motivation. We hypothesise that the observed motivational effect of the Green utopia is driven by perceptions that ordinary people can play a part in bringing about the utopian society, given the many ways in which people can engage in pro-environmental action (e.g. activism, sustainable consumption). In contrast, we speculate that the Sci-Fi utopia may not elicit this perception because the development of new technologies and scientific knowledge is typically not something in which ordinary people are involved.

\section{Participants}

Two hundred and eighty-eight participants were recruited from Mechanical Turk for this study. A sensitivity power analysis using $G^{*}$ Power 3 software indicated a minimum detectable effect size of $\eta_{\mathrm{p}}{ }^{2}=.035$ (small to medium effect) where $1-\beta=.80$. There were 156 males and 132 females, and they had an average age of 35.10 years $(\mathrm{SD}=10.40)$.

\section{Procedure}


Participants were randomly allocated to the same Modern Green, Sci-Fi or control conditions as in Study 1. After the writing task, participants in the utopia conditions completed the same Evaluation measure as in Study 1, as well as a measure of participative efficacy. All participants then completed the measures of strivings and environmental citizenship. In this study, we report all measures, manipulations and exclusions.

Participative Efficacy. Participants rated their agreement (1= strongly disagree, $7=$ strongly agree) with four items assessing the extent to which ordinary people can participate in bringing about the society described in the utopia writing task (e.g. 'Ordinary people can help realize this version of society'). Items were averaged to compute a measure of participative efficacy $(\alpha=.94)$.

Strivings. Participants rated their agreement with $(1=$ strongly disagree, $7=$ strongly agree) 12 items assessing the extent to which they strive to sustain and improve 1) the natural environment, 2) the economy and 3) their personal quality of life. The environmental striving items were taken from Kashima et al.'s (2014) scale, and these items were adapted to create equivalent items assessing economic and life strivings (e.g. 'It is extremely important for me to sustain or improve the natural environment/ the economy/ my quality of life'). All scales showed acceptable reliability, $\alpha>.79$.

Environmental Citizenship. Participants were asked to rate the likelihood $(1=$ very unlikely, $7=$ very likely) that they would engage in 10 different pro-environmental behaviours in the next 12 months (e.g. 'sign a petition in support of protecting the environment', 'give money to an environmental group'). The items were adapted from Bain et al. (2016), and showed adequate reliability, $\alpha=.94$.

\section{Results}


Table 4 about here

One-way ANOVAs with Tukey's post-hoc tests comparing the three conditions on strivings and environmental citizenship showed significant between-group differences for environmental and life striving, and environmental citizenship, but no difference for economic striving (Table 4). The Green utopia was higher than the control condition on environmental and life striving, and was higher than both the Sci-Fi and control conditions on environmental citizenship. Independent samples t-tests comparing the two utopia conditions on Participative Efficacy and Evaluation showed the Modern Green utopia to be rated significantly higher on both.

Table 5 about here

As in Study 1, we tested the effect of Evaluation as a moderator of the relationship between the condition variable $($ Modern Green $=1, \mathrm{Sci}-\mathrm{Fi}=0)$ and the dependent variables. The Condition $\mathrm{x}$ Evaluation interaction was a significant predictor of environmental striving and environmental citizenship (see Table 5).

Figure 2 about here 
Finally, we tested the moderated mediation model depicted in Figure 2. We hypothesised that the Green utopia would give rise to greater participative efficacy, which would in turn predict environmental striving and citizenship; however, this effect would be greater when participants' Evaluation was more positive. Hayes (2013) PROCESS macro was used to obtain conditional indirect effects at various levels of Evaluation. As Table 6 shows, there was only a significant Participative Efficacy x Evaluation interaction for Environmental Striving (thus, the conditional indirect effects for Environmental Citizenship are not presented). The conditional indirect effects presented in the lower part of Table 6 suggest that there was a positive indirect effect of Condition on Environmental Striving through Participative Efficacy, and that this effect was stronger at higher levels of Evaluation.

Table 6 about here

\section{General Discussion}

The present research investigated the effect of the content of utopian visions on motivation for social change. We compared the motivational effects of two major utopian visions derived from previous research and theory - the Green and Sci-Fi utopias. These two major visions differed in several ways. Positive evaluation of the Modern Green utopia was associated with greater social change motivation in general, greater environmental striving and citizenship, and likelihood of donation to an environmental cause, while the Sci-Fi utopia elicited no such motivation (even when it was positively evaluated). The motivational effect of the Green utopia was found to be driven by the perception that this utopia entailed greater participative efficacy, in the form of perceptions that ordinary people can make a difference 
in bringing about the utopian vision. Our results support and extend the findings of Fernando et al. (2018) by showing that utopian visions have motivational effects, but that these are dependent upon the content of those utopias.

There are several possible reasons why we observed no motivational effect of the SciFi utopia, each of which is consistent with our findings of lower participative efficacy: firstly, the Sci-Fi utopia may not elicit social action motivation as it is seen as broadly consistent with existing trends in societal change towards technological advancement (see Kashima et al., 2009; 2011); secondly, ordinary people see limited means by which they can participate in developing of the advanced science and technology upon which the Sci-Fi utopia is dependent (i.e. lower participative efficacy); and thirdly, the Sci-Fi utopia may be viewed as achievable in the very distant future, such that people are unlikely to experience it. Our findings regarding the Sci-Fi utopia suggest the need for greater understanding of the characteristics of a utopian vision which may undermine, rather than facilitate, societal engagement.

Although some of the motivational effects of the Green utopia were specific to proenvironmental behaviours, we should not overstate the domain specificity of the effects of utopian thinking. In Study 1, we observed that - when positively evaluated - the Green utopia was associated with general motivation to change society; and secondly, in Study 2, the Green utopia elicited a significantly greater level of participative efficacy. These variables were not related to pro-environmental behaviours and suggest a broader motivational effect of the Green utopia. In addition, Study 1 showed that participants tended to elaborate on the characteristics of the utopian societies beyond those domains specifically described to them. The Green utopia was seen as not just an environmentally friendly society, but one in which society and its inhabitants possessed a range of other positive characteristics. Thus, the Green utopia appears to represent a broader vision of a peaceful, well-functioning society, perhaps 
representing the ideal of sufficiency, as opposed to the abundance of the Sci-Fi utopia. These broader effects of the Green utopia suggest that the social change motivation elicited by the Green utopia may spread from specifically pro-environmental domains into other aspects of society which form part of a broader, ecologically-sound vision of the ideal society and the good life (see de Geus, 1999).

\section{Implications for Collective Action Theory and Research}

In our introduction we noted that since utopias represent goals for collectives, we can consider actions by people to achieve those goals as collective action. Thus, in addition to focusing on the nature and motivational power of utopian thinking there is wide scope to consider the role that utopian visions may play in established collective action processes and to more thoroughly embed research on utopian thinking within collective action perspectives (especially the SIMCA model). Here we examine a variety of possibilities that warrant further investigation.

Throughout this paper we have conceptualised utopian visions as cognitive alternatives, which may exist prior to the formation of group identities and associated concerns for intergroup injustice. Thus, we reasoned that, aside from participative efficacy, the major elements of collective action motivation (group identification, injustice/anger and moral conviction) would likely be relevant in only some circumstances of utopian thinking, or would require additional variables or processes which were outside the scope of our current investigation. Nevertheless, we can continue to examine the extent to which factors like identification, moral conviction and emotion may modify or strengthen the relationship we have observed between utopian thinking and motivation for action, and thereby continue to develop the theoretical links between utopian thinking and established collective action research and theory. 
First, given its significance within the model and its repeatedly-highlighted role in participation in collective action and social movements (e.g. Drury \& Reicher, 2000; Klandermans, Sabucedo, Rodriguez \& de Weerd, 2002; Simon et al., 1998; Tajfel \& Turner, 1979; van Zomeren et al., 2008), the potential role of group identification in utopian motivation should be considered. There are, in our opinion, two ways in which group identification may play a role. Firstly, the utopian visions of some people may form around, or be concomitant with, already-existing identities (e.g. feminist utopias, libertarian utopias), and identification with those groups may drive utopian action motivation, as well as predicting feelings of group efficacy (perhaps participative efficacy in the more traditional sense of making a difference by contributing to group efforts) and feelings of injustice or anger depending upon the current and historical amount of power and privilege associated with the identity.

Utopian visions may also represent a step prior to the process of group or identity formation - a separable cognitive alternative to the status quo that drives social identification with a collective (see Tajfel \& Turner, 1979). Smith et al. (2015) propose that identity formation can begin with an individual's recognition of a conflict between the way things are and the way they could be. A utopian vision is a particularly rich and compelling version of 'the way things could be', which may give rise to a comparison with the way things are, and the recognition of a conflict. If, as Smith et al. (2015) suggest, that vision is communicated to others, receives assent and develops into consensus, a new collective identity may form around the values or norms expressed by the utopia. Clearly, this involves several additional processes, but suggests that utopian motivation may both drive, and be enhanced by, the formation of collective identities in the form of, for example, opinion-based groups with a particular utopian vision at their core (Bliuc, MacGarty, Reynolds \& Muntele, 2007). 
Next, although we have argued that intergroup injustice (and concomitant feelings of anger) need not be an element of utopian thinking, utopian visions may be involved in collective action to address intergroup disadvantage. For example, while intergroup disadvantage may not be the way that many people currently think about green behaviour it may soon become more common. The uneven impact of climate change across different parts of the world has already begun to spark discourse around climate change-disadvantaged communities and countries. As noted above, a utopian vision can serve as the cognitive alternative (which suggests that the intergroup relationship is susceptible to change) needed by disadvantaged groups before they can mobilise for change. To the extent that a utopian vision does serves as this alternative, it will then provide the basis for judgements about the 'way things should be', setting in train the processes identified by the SIMCA model. As van Zomeren et al. (2018) note, identity content is a neglected area in collective action research, and utopian visions offer a valuable way forward.

Alternatively, while anger in response to intergroup injustice is the emotion which has most often been identified as motivating action (e.g. van Zomeren et al., 2004), a broader perspective on the emotions elicited by utopian thinking (and the cognitions underlying them) may further enrich our understanding of utopian motivation and collective action. Several utopian theorists have pointed to the fundamental role of hope in utopian thinking (see e.g. Bloch, 1986; Browne, 2005; Levitas, 2004), and this may suggest an alternative pathway by which utopian visions have motivational effects. Indeed, recent research (Cohen-Chen \& van Zomeren, 2018; Greenaway, Cichocka, van Veelen, Likki \& Branscombe, 2016) has begun to examine the role of hope in collective action and social change. This research suggests that feelings of hope especially act on the experience of efficacy (either as a predictor of greater group efficacy, or a moderator of the effect of efficacy beliefs on action intentions). Examining hope in (and the extent to which it may vary between) utopian visions provides an 
opportunity to understand the role of this emotion in bringing about action for collective goals (which has been relatively under-researched in the collective action literature).

Both hope theory (Snyder, 2002) and achievement motivation theories such as Oettingen's (2012) entail the consideration of feasible routes to the attainment of goals. In hope theory, this is conceptualised as 'pathways thinking' and describes the production of a route, or perhaps several alternative routes, to a goal. Similarly, Oettingen's fantasy realisation research shows that goal pursuit is facilitated by mentally contrasting the desired outcome with the current reality, and a recognition of the reality 'standing in the way' of the desired future. Thus, both theories suggest that merely thinking about a desired outcome is insufficient; one must consider the current reality and the potential pathways leading to that outcome. Here, again, is another mechanism by which the Green and Sci-Fi utopias may be distinguished. While previous research has shown evidence of a prevalent beliefs that societies are becoming more developed and technological over time (Kashima et al., 2009; 2011), a significant change in course is required for the achievement of an environmentally sound society. Thus, the Green utopia may more naturally invoke these kinds of pathways thinking or mental contrasting, resulting in greater hope and energisation towards goal.

Finally, recent research has examined the role of moral conviction in collective action (see van Zomeren et al., 2018). People often pursue action to promote causes which agree with their morality, or to oppose things which they consider to be immoral - i.e. these issues are moralised. Those who moralise an issue have been shown to be more motivated to defend those moral beliefs (Skitka, 2010). Utopian visions express important values but are likely to vary in the extent to which they can express strong moral convictions, or to which they reflect moral aspirations or respond to perceived moral violations. To what extent do specific utopian visions imply a moral conviction, and does this strengthen motivation for action, or increase the salience, or indeed the development, of collective identities around moral 
convictions (see Kutlaca, van Zomeren \& Epstude, 2019)? For example, a pathway by which the Green utopia may be more likely to elicit social change motivation is because people see it as their moral duty to protect and preserve the natural environment or see its destruction as immoral (see Feinberg \& Willer, 2013; Schultz \& Zelezny, 1998; Stern, Dietz, Abel, Guagnano \& Kalof, 1999), and it is possible that this would enhance one's sense of identification as 'green' or 'environmentalist'. By contrast, the Sci-Fi utopia, characterised by the pursuit of material abundance, would seem not to entail this kind of moral motivation.

\section{Limitations}

Although we have demonstrated the motivational effects of the Green utopia, it remains a possibility that the difference between those and the effects of the Sci-Fi utopia may not be quite as stark as shown here. One possibility is that our dependent measures did not adequately represent the kinds of motivation elicited by the Sci-Fi utopia. While we attempted to address this in both our studies by using, for example, measures of economic striving and donations to a medical research body, these may not have fully captured the motivation toward abundance and technological development expressed in the Sci-Fi utopia. Future research may continue to investigate the motivational effects of the Sci-Fi utopia using more targeted dependent measures; for instance, the desire to participate in, be educated about, or contribute money towards, the development of specific technologies, or donations to organisations promoting scientific research and technological development such as Students for the Exploration and Development of Space, or the Cultured Meat Foundation. Nevertheless, as we noted in regard to the Green utopia, we do not believe this limitation should be overstated; the Sci-Fi utopia, in addition to eliciting low motivation on these more specific measures, produced lower levels of generalized social change motivation and was characterised by lower levels of a range of positive societal traits (e.g. warmth, positive emotion, social progress) for which people may be motivated to strive. 
A second limitation pertains to our measurement of the concept of participative efficacy. Here we have shown that the perception that ordinary people can make a difference in achieving the utopian vision predicts social change motivation; however (as we have acknowledged), our measurement of participative efficacy diverges somewhat from its typical conceptualisation in the collective action literature as the perception that individuals can act, as part of a group, to make a difference (see van Zomeren et al., 2013). Our contention has been that, given that utopian visions represent cognitive alternatives which are conceptually prior to the formation of groups or group identities, it is sensible to assess a slightly modified version of this concept (which omits the group aspect). Nevertheless, it is worth considering further whether the concept measured here is a form of participative efficacy, or a similar - but distinct - concept. Future research may wish to use both forms of measurement in the context of studying collective action or utopian thinking to examine the construct validity of the measure used here.

A final limitation of this research is that it is restricted to only two utopian visions. Although we argue that these are two predominant contemporary utopian visions arising from extant research and theory, we do not expect that people's utopian visions are restricted to these themes. The development of a typology of ordinary people's utopian visions, and their capacity to motivate social change behaviour, is an important next step. Creating this kind of typology would also alert us to other common utopian visions which might share the motivating features of the Green utopia, and thereby also elicit societal change motivation. For example, it has been shown here and elsewhere (Bain et al., 2013) that possible societies which are viewed as containing greater interpersonal warmth tend to motivate greater change orientation. Among previous typologies of utopian visions (e.g., Davis, 1981), the so-called Moral Commonwealth (a society in which all people cooperate and act morally) is a prominent prototype. Would the implied warmth and morality of this kind of society generate 
similar levels of efficacy beliefs and motivation as the Green utopia? Testing across a larger set of utopian visions can help us to identify the more fundamental features underlying the motivational effects of utopian thinking.

\section{Future Directions}

Given the motivating effects of the Green utopia, further investigation of this theme of utopianism is warranted in two areas. As utopian theorists have noted (e.g. Garforth, 2005), a distinction can be made between modern and primitivist Green utopias, and these are two of potentially several specific utopian visions that may fall under the umbrella of 'Green Utopia'. As we observed regarding the Green and Sci-Fi utopias, different utopian visions are perceived as entailing a variety of other characteristics which make up a more complete vision of society. In the same way, different varieties of the Green utopia are likely to differ in their attitudes to wider issues such as growth, human ingenuity, liberation and human cooperation (see Cotgrove, 1976). We chose to concentrate on the modern Green utopia given its contemporary relevance; however, the more Arcadian utopia (or, indeed, other kinds of pro-environmental utopia) may also be associated with social change motivation. These other pro-environmental utopias would also embody the moderation or sufficiency principle which has been shown to characterise people's ideals for the self and society, and on that basis, we may expect them to generate positive evaluations. It is likely, however, that these other utopias may generate a different kind of change motivation. As Stern (2000) has noted, environmentally significant behaviour can be organized into several categories - activism, public sphere behaviour, and private sphere behaviour. Here, we have largely concentrated on public sphere motivations (e.g. citizenship behaviour, donations to organizations), but it is possible that, for example, an Arcadian utopia may motivate private sphere actions consistent with a primitivist green ethos (e.g., voluntary simplicity, growing one's own food). 
In Study 2, we observed the moderated mediation effect of the Green utopia via participative efficacy for environmental striving but not environmental citizenship. It may be that while we were able to predict a more general pro-environmental orientation, the more specific citizenship actions did not exactly match the motivation elicited by utopian thinking. Future research may explore the range of specific motivations within a given domain (e.g. pro-environmental motivation) and those which are most likely to be motivated by a given utopian vision.

Finally, we have outlined several ways in which research on utopian motivation could be influenced by existing theories of collective action. Our theorising about these connections can generate many new research directions that empirically investigate the roles of key components of collective action models in the context of utopian thinking. A key question in linking these two strands of research will be how the motivational capacity of utopian visions is affected by being driven by group identification, or driving group identification, much in the same way as Thomas et al. (2011) compared the role of identification in the EMSICA and SIMCA models. Further research directions include investigations of the effects of the emotional consequences of utopian thinking, and the moralization of utopian visions.

\section{Conclusion}

Theorizing and research on utopias points to a potentially novel direction for the psychology of social change. An important step in this research is to understand how the content of utopian visions is associated with citizens' engagement with their society and participation in the provision of public goods. Future research can continue to investigate the extent to which utopian motivation is consistent with, or expands upon, existing understandings of collective action and social change. 


\section{References}

Bain, P. G., Hornsey, M.J., Bongiorno, R., Kashima, Y., \& Crimston, D. (2013) Collective futures: How projections about the future of society are related to actions and attitudes supporting social change. Personality and Social Psychology Bulletin, 39, 523-539.

Bain, P.G., Milfont, T.L., Kashima, Y., Bilewicz, M., Doron, G., Gardarsdottir, R.B., ... Saviolidis, N.M. (2016) Co-benefits of addressing climate change can motivate action around the world. Nature Climate Change, 6, 154-157.

Bandura, A. (1982) Self-efficacy mechanism in human agency. American Psychologist, 37, $122-147$.

Bandura, A. (1986) The explanatory and predictive scope of self-efficacy theory. Journal of Social and Clinical Psychology, 4, 359-373.

Bliuc, A-M., McGarty, C., Reynolds, K. \& Muntele, D. (2007) Opinion-based group membership as a predictor of commitment to political action. European Journal of Social Psychology, 37, 19-32.

Bloch, E. (1986) The Principle of Hope. (S. Plaice, N. Plaice \& P. Knight, trans.) Oxford: Blackwell.

Browne, C. (2005) Hope, critique, and utopia. Critical Horizons, 6, 63-86.

Carey (1999) The Faber Book of Utopias. London: Faber.

Carver, C.S. \& Scheier, M.F. (1981) Attention and Self-regulation. New York: Springer.

Carver, C.S. \& Scheier, M.F. (1998) On the Self-Regulation of Behavior. New York: Cambridge University Press. 
Chomsky, N. (1970/1999) Language and Freedom. Resonance, 4, 86-104.

Cohen, M.J. (1998) Science and the environment: Assessing cultural capacity for ecological modernization. Public Understanding of Science, 7, 149-167.

Cohen-Chen, S. \& van Zomeren, M. (2018) Yes we can? Group efficacy beliefs predict collection action, but only when hope is high. Journal of Experimental Social Psychology, 77, 50-59.

Cotgrove (1976) Environmentalism and utopia. Sociological Review. 24, $23-42$.

Davis, J.C. (1981) Utopia and the Ideal Society: A Study of English Utopian Writing, 15161700. New York: Cambridge University Press.

De Geus (1999) Ecological Utopias: Envisioning the Sustainable Society. Utrecht: International Books.

Drury, J. \& Reicher, S. (2000) Collective action and psychological change: The emergence of new social identities. British Journal of Psychology, 39, 579-604.

Dunlap, R.E. \& Van Liere, K.D. (1984) Commitment to the dominant social paradigm and concern for environmental-quality. Social Science Quarterly, 65, 1013-1028.

Emmons, R.A. (1986) Personal strivings: An approach to personality and subjective wellbeing. Journal of Personality and Social Psychology, 51, 1058-1068.

Emmons, R.A. \& King, L.A. (1989) Personal striving differentiation and affective reactivity. Journal of Personality and Social Psychology, 56, 478-484.

Feather, N. (1982) Expectations and Actions: Expectancy-Value Models in Psychology. Hillsdale, N.J.: Erlbaum Associates. 
Feinberg, M. \& Willer, R. (2013) The moral roots of environmental attitudes. Psychological Science, 24, 56-62.

Fernando, J.W., Burden, N., Ferguson, A., O’Brien, L.V., Judge, M. \& Kashima, Y. (2018) Functions of utopia: How utopian thinking motivates societal engagement. Personality and Social Psychology Bulletin, 44, 779-792.

Fernando, J.W., Burden, N.J. \& Kashima, Y. (2019) Possible and ideal societies. Unpublished manuscript.

Fisher, D.R. \& Freudenburg, W.R. (2001) Ecological modernization and its critics: Assessing the past and looking toward the future. Society and Natural Resources, 14, 701-709.

Fitting, P. (2010) Utopia, dystopia and science fiction. In In G.Claeys (Ed.), The Cambridge Companion to Utopian Literature (pp. 135-153), Cambridge: Cambridge University Press.

Garforth, L. (2005) Green utopias: Beyond apocalypse, progress and pastoral. Utopian Studies, 16, 393-427.

Greenway, K.H., Cichocka, A., van Veelen, R., Likki, T. \& Branscombe, N.R. (2016) Feeling hopeful inspires support for social change. Political Psychology,37, 89-107.

Hayes, A.F. (2013) Introduction to Mediation, Moderation, and Conditional Process Analysis: A Regression-based Approach. New York, NY: Guilford Press.

Higgins, E.T. (1987) Self-discrepancy: A theory relating self and affect. Psychological Review, 94, 319-340.

Hornsey, M.J., Bain, P.G., Harris, E.A., Lebedeva, N., Kashima, E.S., Guan, Y., ... Blumen, S. (2018) How much is enough in a perfect world? Cultural variation in ideal levels of 
happiness, pleasure, freedom, health, self-esteem, longevity, and intelligence. Psychological Science, 29, 1393-1404.

Jost, J.T., Badaan, V., Goudarzi, S., Hoffarth, M. \& Mogami, M. (2019) The future of system justification theory. British Journal of Social Psychology, 58, 382-392.

Kaplowitz, M.D., Lupi, F., Yeboah, F.K. \& Thorp, L.G. (2011) Exploring the middle ground between environmental protection and economic growth. Public Understanding of Science, 22, 413-426.

Karau, S. J., \& Williams, K. D. (1993). Social loafing: A meta-analytic review and theoretical integration. Journal of Personality and Social Psychology, 65(4), 681.

Kashima, Y., Bain, P., Haslam, N., Peters, K., Laham, S., Whelan, J. ... \& Fernando, J. (2009) Folk theory of social change. Asian Journal of Social Psychology, 12, 227246.

Kashima, Y., Paladino, A., \& Margetts, E. (2014). Environmentalist identity and environmental striving. Journal of Environmental Psychology, 38, 64-75.

Kashima, Y., Shi, J., Tsuchiya, L., Kashima, E.S., Cheng, S.Y., Chao, M.M. \& Shin, S.H. (2011) Globalization and folk theory of social change: How globalization relates to societal perceptions about the past and future. Journal of Social Issues, 67, 696-715.

Kilbourne, W.E., Beckman, S.C. \& Thelen, E. (2002) The role of the dominant social paradigm in environmental attitudes: A multination examination. Journal of Business Research, 55, 193-204.

Klandermans, B. (1984) Mobilization and participation: Social psychological expansions of resource mobilization theory. American Sociological Review, 5, 583-600. 
Klandermans, B., Sabucedo, J.M., Rodriguez, M. \& de Weerd, M. (2002) Identity processes in collective action participation: Farmers' identity and farmers' protest in the Netherlands and Spain. Political Psychology, 23, 235-251.

Kozinets, R. V. (2001). Utopian enterprise: Articulating the meanings of Star Trek's culture of consumption. Journal of Consumer Research, 28, 67-88.

Kumar, K. (1987) Utopia and Anti-Utopia in Modern Times. Oxford: Blackwell.

Kutlaca, M., van Zomeren, M., \& Epstude, K. (2019) Our right to a steady ground: Perceived rights violations motivate collective action against human-caused earthquakes. Environment and Behavior, 51, 315-344.

Levitas, R. (1990) The Concept of Utopia. London: Philip Allan.

Levitas, R. (2004) Hope and education [Review of the book Hope and education: The role of the Utopian imagination by D. Halpin]. Journal of Philosophy and Education, 38, 269-273.

Mannheim, K. (1991) Ideology and Utopia: An Introduction to the Sociology of Knowledge (L. Wirth \& E. Shils trans.) London: Routledge.

Markus, H. \& Nurius, P. (1986) Possible selves. American Psychologist, 41, 954-969.

McGarty, C., Bliuc, A.M., Thomas, E.F. \& Bongiorno, R. (2009) Collective action sa the material expression of opinion-based group membership. Journal of Social Issues, 65, 839-857.

Mol, A.P. \& Spaargaren, G. (2000) Ecological modernisation theory in debate: A review. Environmental Politics, 9, 17-49. 
Mummendey, A., Kessler, D.A., Klink, A. \& Mielke, R. (1999) Strategies to cope with negative social identity: Predictions by social identity theory and relative deprivation theory. Journal of Personality and Social Psychology, 76, 229-245.

Oettingen, G. (2012) Future thought and behaviour change. European Review of Social Psychology, 23, 1-63.

Pepper, D. (2007) Tensions and dilemmas of ecotopianism. Environmental Values, 16, 289312.

Polak, F.L. (1961) The Image of the Future; Enlightening the Past, Orienting the Present, Forecasting the Future (E.Boulding trans.) New York: Oceana.

Reicher, S.D., Haslam, S.A., Spears, R. \& Reynolds, K.J. (2012) A social mind: The conext of John Turner's work and its influence. European Review of Social Psychology, 23, 344-385.

Sargent, L.T. (1994) The three faces of utopianism revisited. Utopian Studies, 5, 1-37.

Schultz, P.W. \& Zelezny, L.C. (1998) Values and proenvironmental behaviour: A fivecountry survey. Journal of Cross-Cultural Psychology, 29, 540-558.

Segal, H. P. (2012). Utopias: A brief history from ancient writings to virtual communities. Oxford, UK: Wiley-Blackwell.

Simon, B., Loewy, M., Sturmer, S., Weber, U., Freytag, P., Habig, C., ... Spahlinger, P. (1998) Collective identification and social movement participation. Journal of Personality and Social Psychology, 74, 646-658.

Skitka, L.J. (2010) The psychology of moral conviction. Social and Personality Psychology Compass, 4, 267-281. 
Smith, L.G.E., Thomas, E.F. \& McGarty, C. (2015) "We must be the change we want to see in the world": Integrating norms and identities through social interaction. Political Psychology, 36, 543-557.

Snyder, C.R. (2002) Hope theory: Rainbows in the mind. Psychological Inquiry, 13, 249-275.

Spaargaren, G. \& Mol, A.P. (1992) Sociology, environment, and modernity: Ecological modernization as a theory of social change. Society \& Natural Resources, 5, 323-344.

Stableford, B. (2010) Ecology and dystopia. In G.Claeys (Ed.), The Cambridge Companion to Utopian Literature (pp. 259-281), Cambridge: Cambridge University Press.

Stern, P.C. (2000) Toward a coherent theory of environmentally significant behavior. Journal of Social Issues, 56, 407-424.

Stern, P.C., Dietz, T., Abel, T., Guagnano, G.A. \& Kalof, L. (1999) A value-belief-norm theory of support for social movements: The case of environmentalism. Human Ecology Review, 6, 81-97.

Tajfel, H. \& Turner, J.C. (1979) An integrative theory of intergroup conflict. In W.G. Austin \& S. Worchel (Eds.) The Social Psychology of Intergroup Relations (pp.7-24) Monterey, CA: Brooks/Cole.

Thomas, E.F., Mavor, K.I. \& McGarty, C. (2011) Social identities facilitate and encapsulate action-relevant constructs: A test of the social identity model of collective action. Group Processes \& Intergroup Relations, 15, 75-88.

van Zomeren, M. (2016) Building a tower of Babel? Integrating core motivations and features of social structure into the political psychology of political action. Advances in Political Psychology, 37, 1-28. 
van Zomeren, M. (2019) Toward a cultural psychology of collective action: Just how "core" are the core motivations for collective action. Journal of Pacific Rim Psychology, 13, $1-7$.

van Zomeren, M. \& Iyer, A. (2009) Toward an integrative understanding of the social and psychological dynamics of collective action. Journal of Social Issues, 65, 645-660.

van Zomeren, M., Kutlaca, M. \& Turner-Zwinkels, F. (2018) Integrating who "we" are with what "we" (will not) stand for: A further extension of the Social Identity Model of Collective Action. European Review of Social Psychology, 29, 122-160.

van Zomeren, M., Postmes, T., \& Spears, R. (2008) Toward an integrative social identity model of collective action: A quantitative research synthesis of three sociopsychological perspectives. Psychological Bulletin, 134, 504-535.

van Zomeren, M., Saguy, T., \& Schellhaas, F.M.H. (2013) Believing in "making a difference" to collective efforts: Participative efficacy beliefs as a unique predictor of collective action. Group Processes \& Intergroup Relations, 16, 618-634.

van Zomeren, M., Spears, R., Fischer, A.H., \& Leach, C.W. (2004) Put your money where your mouth is! Explaining collective actions tendencies through group-based anger and group efficacy. Journal of Personality and Social Psychology, 87, 649-664.

Wright, S. C. (2009) The next generation of collective action research. Journal of Social Issues, 65, 859-879.

Wright, S.C, Taylor, D.M., \& Moghaddam, F.M. (1990) Responding to membership in a disadvantaged group: From acceptance to collective protest. Journal of Personality and Social Psychology, 58, 994-1003. 
Xiao, C. (2013) Public attitudes toward science and technology and concern for the environment: Testing a model of indirect feedback effects. Environment and Behavior, 45, 113-137. 
Table 1.

Multiple Regression Analysis Predicting Society Characteristics, Study 1.

\begin{tabular}{lcccccc}
\hline & Warmth & Competence & $\begin{array}{c}\text { Social } \\
\text { dysfunction }\end{array}$ & $\begin{array}{c}\text { Social } \\
\text { progress }\end{array}$ & $\begin{array}{c}\text { Negative } \\
\text { emotion }\end{array}$ & $\begin{array}{c}\text { Positive } \\
\text { emotion }\end{array}$ \\
\hline Green/Sci-Fi & $.29^{* * *}$ & -.05 & -.09 & $.19^{*}$ & $-.18^{*}$ & $.15^{*}$ \\
Evaluation & $.75^{* * *}$ & $.38^{* *}$ & $-.56^{* * *}$ & $.61^{* * *}$ & $-.79^{* * *}$ & $.78^{* * *}$ \\
Evaluation x Condition & -.04 & $.26^{*}$ & .07 & .07 & .20 & -.06 \\
$F(3,78)$ & $52.04^{* * *}$ & $13.00^{* * *}$ & $10.64^{* * *}$ & $26.14^{* * *}$ & $28.96^{* * *}$ & $39.09^{* * *}$ \\
$R^{2}$ & .67 & .33 & .29 & .50 & .53 & .60 \\
\hline${ }^{* * * *} p<.001,{ }^{* *} p<.01,{ }^{*} p<.05$ & & & & & &
\end{tabular}

Table 2.

One-Way ANOVAs for Utopia Functions across Utopia Prototypes, Study 1.

\begin{tabular}{lcccccc}
\hline & Green & Sci-Fi & Ordinary Day & $F(2,121)$ & $p$-value & $\eta^{2} \mathrm{p}$ \\
\hline Compensation & $4.29(1.51)$ & $4.34(1.58)$ & $3.93(1.49)$ & 0.91 & .41 & .02 \\
Criticism & $5.37(1.14)$ & $5.31(1.36)$ & $4.92(1.43)$ & 1.45 & .23 & .02 \\
Change & $5.13(1.41)$ & $5.08(1.59)$ & $4.73(1.45)$ & 0.41 & .41 & .02 \\
\hline
\end{tabular}

Table 3.

Logistic Regression Analysis Predicting Donation to Charity, Study 1.

\begin{tabular}{lcccccccc}
\hline & \multicolumn{2}{c}{ Sierra Club } & \multicolumn{2}{c}{ PBS } & \multicolumn{3}{c}{ Salvation Army } & \multicolumn{2}{c}{ Cancer Society } \\
\hline & $\mathrm{B}(\mathrm{SE})$ & $\mathrm{OR}$ & $\mathrm{B}(\mathrm{SE})$ & $\mathrm{OR}$ & $\mathrm{B}(\mathrm{SE})$ & $\mathrm{OR}$ & $\mathrm{B}(\mathrm{SE})$ & $\mathrm{OR}$ \\
\hline Condition & $-.50(.64)$ & 0.61 & $-.27(.58)$ & 0.76 & $-.38(.57)$ & 0.69 & $-.14(.47)$ & 0.87 \\
Evaluation & $-.09(.17)$ & 0.92 & $.04(.17)$ & 1.04 & $.14(.18)$ & 1.15 & $-.07(.16)$ & 0.94 \\
Evaluation x Condition & $.81^{*}(.36)$ & 2.24 & $.57^{\dagger}(.33)$ & 1.76 & $.27(.32)$ & 1.31 & $.21(.25)$ & 1.24 \\
Nagelkerke R $^{2}$ & .13 & & .11 & & .06 & & .01 & \\
\hline
\end{tabular}


Table 4.

One-Way ANOVAs for Dependent Variables across Utopia Prototypes, Study 2.

\begin{tabular}{lccccc}
\hline & Green & Sci-Fi & Ordinary Day & $F(2,285) / t(187)$ & $\eta^{2} / d$ \\
\hline Environmental Striving & $5.00_{\mathrm{a}}(1.24)$ & $4.69_{\mathrm{ab}}(1.40)$ & $4.46_{\mathrm{b}}(1.24)$ & $4.29^{*}$ & .03 \\
Economic Striving & $5.32(1.03)$ & $5.39(1.10)$ & $5.09(1.15)$ & 1.88 & .01 \\
Life Striving & $4.38_{\mathrm{a}}(1.25)$ & $4.22_{\mathrm{ab}}(1.37)$ & $3.88_{\mathrm{b}}(1.30)$ & $3.72^{*}$ & .03 \\
Environmental Citizenship & $4.05_{\mathrm{a}}(1.71)$ & $3.27_{\mathrm{b}}(1.58)$ & $3.35 \mathrm{~b}(1.61)$ & $6.70^{* *}$ & .05 \\
Participative Efficacy & $5.12_{\mathrm{a}}(1.44)$ & $4.43_{\mathrm{b}}(1.59)$ & & $4.94^{* * *}$ & .45 \\
Evaluation & $5.54_{\mathrm{a}}(1.68)$ & $4.25_{\mathrm{b}}(1.92)$ & & $3.11^{* *}$ & .72 \\
\hline
\end{tabular}
${ }^{* * * *} p<.001, * * p<.01,{ }^{*} p<.05$

N.B. Common subscripts indicate no significant difference between conditions.

Table 5 .

Regression Analysis Predicting Strivings and Citizenship from Utopia Prototypes and Evaluations, Study 2

\begin{tabular}{lcccc}
\hline & $\begin{array}{c}\text { Environmental } \\
\text { Striving }\end{array}$ & Life Striving & Economic Striving & $\begin{array}{c}\text { Environmental } \\
\text { Citizenship }\end{array}$ \\
\hline Condition (Green v Sci-Fi) & -.07 & .10 & -.01 & $-.16^{*}$ \\
Evaluation & $.41^{* * *}$ & $.31^{* *}$ & .17 & $.38^{* * *}$ \\
Condition x Evaluation & $-.35^{* *}$ & -.13 & -.03 & $-.22^{*}$ \\
$F(3,185)$ & $5.79^{* *}$ & $3.15^{*}$ & 1.44 & $8.30^{* * *}$ \\
$R^{2}$ & .09 & .05 & .02 & .12 \\
${ }^{* * * *} p<.001, * * p<.01,{ }^{*} p<.05$ & & & &
\end{tabular}

Table 6.

Results of Moderated Mediation Analysis, Study 2.

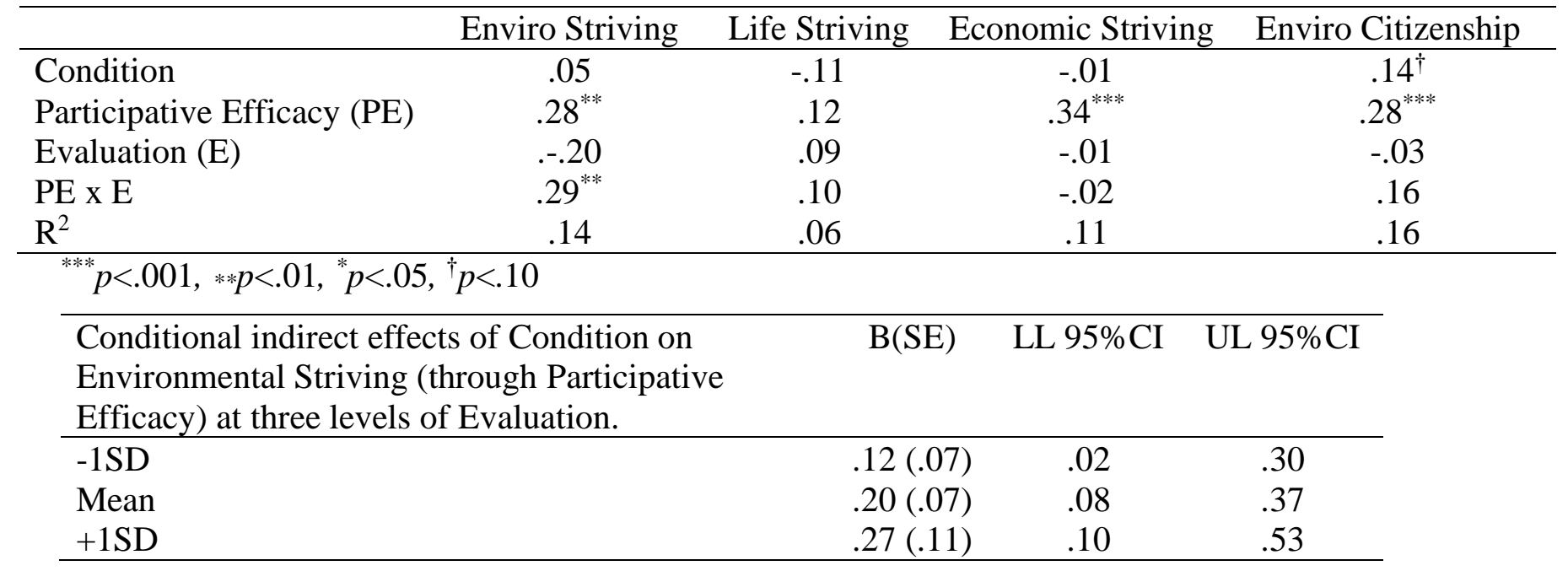


Figure Captions

Figure 1. Condition x Evaluation Interaction Effect on Probability of Donation to Sierra Club Figure 2. Hypothesised moderated mediation model. 


\section{Appendix A}

\section{Utopian function scale, Study 1}

I feel the current society is a pale shadow of an ideal world.

I feel there are so many things that are wrong about the current world.

I feel disgusted or even angry about the current world.

I feel like forgetting about the current world, and just enjoying an ideal world.

I feel like escaping from the current world and feel like dreaming about an imagined ideal world.

I feel like just living in an ideal world, the world that I would love to live in.

I feel like doing something to change the world, so we can make the world better.

I feel a strong urge to do something about the current world, so that we can improve it.

I feel something has to be done, so we can move closer to the ideal. 


\section{University Library}

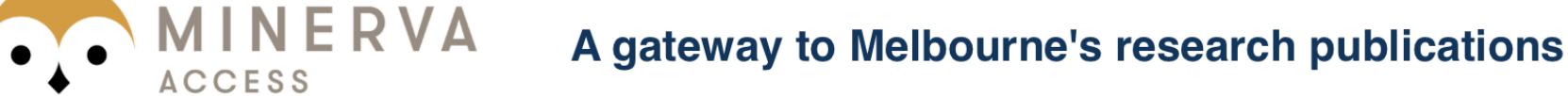

Minerva Access is the Institutional Repository of The University of Melbourne

Author/s:

Fernando, JW;O'Brien, LV;Burden, NJ;Judge, M;Kashima, Y

Title:

Greens or space invaders: Prominent utopian themes and effects on social change motivation

Date:

2019-07-21

\section{Citation:}

Fernando, J. W., O'Brien, L. V., Burden, N. J., Judge, M. \& Kashima, Y. (2019). Greens or space invaders: Prominent utopian themes and effects on social change motivation. EUROPEAN JOURNAL OF SOCIAL PSYCHOLOGY, 50 (2), pp.278-291. https:// doi.org/10.1002/ejsp.2607.

Persistent Link:

http://hdl.handle.net/11343/252748 